\title{
신생아 파상풍
}

\author{
Itzhak Brook
}

Department of Pediatrics, Georgetown University School of Medicine, Washington DC, United States

\section{Neonatal tetanus}

\author{
Itzhak Brook \\ Department of Pediatrics, Georgetown University School of Medicine, Washington DC, United States
}

Neonatal tetanus, also known as tetanus neonatorum, occurs in young infants of inadequately immunized mothers. It is a kind of generalized tetanus that is exhibited mainly by prevention of the release of the inhibitory neurotransmitters (i.e., disinhibition) and is initiated by tetanospasmin, an exotoxin created by Clostridium tetani. Contamination of the umbilical cord stump is the main cause. The typical, early manifestations are weakness and lack of ability to suck, continuing within hours to trismus, risus sardonicus, and ultimately generalized tetanic spasm, rigidity, and opisthotonus. Without treatment, neonatal tetanus has a poor outcome with a mortality rate above $90 \%$. Mortality can result from asphyxia due to the spasm and hypersympathetic state. The managing goals are to neutralize its toxin, eradicate $C$. tetani, care for wound, and offer supportive care, such as mechanical ventilation, parenteral nutrition, sedation, neuromuscular blockade, and management of autonomic dysfunction.

Key words: Immunization, Passive; Infant, Newborn; Seizures; Tetanus; Vaccination

\section{Introduction}

Tetanus is caused by tetanospasmin, also known as tetanus toxin, an exotoxin produced by Clostridium tetani. Neonatal tetanus (NT), also known as tetanus neonatorum, is a chief cause of infant mortality in developing countries ${ }^{1-3)}$. It is estimated that the entity led to 787,000 and 200,000 deaths worldwide in

Received: May 13, 2021

Revised: May 29, 2021

Accepted: May 29, 2021

\section{Corresponding author}

Itzhak Brook (ORCID 0000-0001-6068-1475)

Department of Pediatrics, Georgetown University School of Medicine, 3800 Reservoir Road, NW, Washington DC 20007, United States

Tel: +1-202-363-4253 Fax: +1-202-363-4253

E-mail: ib6@georgetown.edu
1988 and in 2000, respectively ${ }^{3)}$. The latest World Health Organization estimate shows is 25,000 deaths from NT in 2018, which means an $88 \%$ reduction from the situation in 20003). Maternal tetanus and NT have not yet been eliminated by July 2019 in 12 countries $^{3)}$. Unlike in low and middle-income countries, NT is rare and was reported in only 2 newborns from 2009 to 2015 in the United States ${ }^{3)}$.

\section{Main subject}

\section{Bacteriology and pathogenesis}

C. tetani is a thin, gram-positive, non-encapsulated, motile, obligated anaerobic bacillus that exists in vegetative and sporulated forms. The spores are 
terminal and drumstick in appearance, and withstand heat or chemical disinfection. However, the vegetative forms can be killed by chemical disinfectants (glutaraldehyde, iodine, and hydrogen peroxide), heat, and some antimicrobials ${ }^{4}$. Spores are present in soil and the gastrointestinal tract of mammals; they are nonpathogenic in earth or contaminated animal tissues until conditions are suitable for alteration to the vegetative (pathogenic) forms. Such conditions emerge when oxygen concentration decreases in the devitalized tissue by either foreign body, injury (primarily crush) or suppuration.

Although $C$. tetani itself does not invade the tissue, this bacterium induces illness through production of tetanospasmin ${ }^{4-7)}$. Toxigenic $C$. tetani strains encode tetanospasmin on a plasmid ${ }^{5}$, and the toxin is produced by the proliferating $C$. tetani at the location of infection. The toxin acts in the central nervous system to prevent the discharge of inhibitory neurons, thereby disinhibiting the motor neurons. Unlike botulinum toxins, it has no action at the neuromuscular junctions. Its action is as a metalloprotease preventing the release of glycine and $\gamma-$ aminobutyric acid ${ }^{5}$. The neuromuscular endplates and motor nuclei of the central nervous system are stimulated by tetanospasmin, thus generating muscle spasm and convulsions.

The absorption and transport of tetanospasmin have 2 mechanisms ${ }^{7}$. When a large amount of the toxin is produced, it spreads to the neurons via the circulation and lymphatics, causing spasm at distant sites and initially affecting the muscles with shortest neural path. The toxin undergoes transcytosis and interneural transfer, resulting in effects distant from the toxin production sites ${ }^{5}$. Lockjaw and risus sardonicus are manifestations of this fast-developing illness. The inception of muscular involvement relates to the neural distance from the toxin production sites ${ }^{5-7)}$.

Nidogen-1 and nidogen-2, extracellular matrix proteins, are the receptors of tetanospasmin that reach the nervous system through the neuromuscular junctions. These proteins spread backward transsynaptically, shielded from neutralizing anti- toxins, to the inhibitory synapses where the proteins bind and permanently prevent the secretion of acetylcholine $e^{8}$. The lower motor neurons become uninhibited, increasing the tone of agonist and antagonist muscles. This increase in muscle tone produces the typical confined spasm and rigidity.

Tetanospasmin also can generate paralysis by stopping transmission at the neuromuscular junctions ${ }^{9}$. Some clinical manifestations indicate the involvement of the sympathetic nervous system. The lasting effect of the toxin may be reduced by the neuronal generation of additional branches and the creation of new links among the surviving neurons ${ }^{5,7)}$.

\section{Clinical manifestations}

NT is a generalized tetanus that usually occurs only in infants delivered from unimmunized or inadequately immunized mothers. Causes of this entity include infection of the umbilical stump, inadequate obstetric care, delivery away from medical facilities, poor obstetrical care following delivery, and cultural routines such as application of cow stool or soiling over the umbilical stump. The incidence of NT may be reduced by the immunization of adolescent and adult women, and local use of antimicrobials on the stump.

Weakness and failure to suck are the most frequent initial manifestations that usually occur in 57 days (range, 3-24 days) after birth. These symptoms continue to develop from an initial trismus and sucking difficulty to risus sardonicus within hours, and subsequently to generalized tetanic spasm, rigidity, and opisthotonus (Fig. 1) ${ }^{6}$. Affected infants stay awake despite the spasm.

NT has a poor prognosis with a mortality rate over $90 \%$. This outcome can be caused by the hypersympathetic state. The most frequent causes of mortality are apnea during the first 7 days and septicemia in 7-14 days often due to infection starting at the umbilical stump ${ }^{6}$. Other complications include pneumonia, atelectasis, hemorrhage from the lung or central nervous system, renal failure, electrolyte imbalance, and laryngospasm. Younger age and lower 


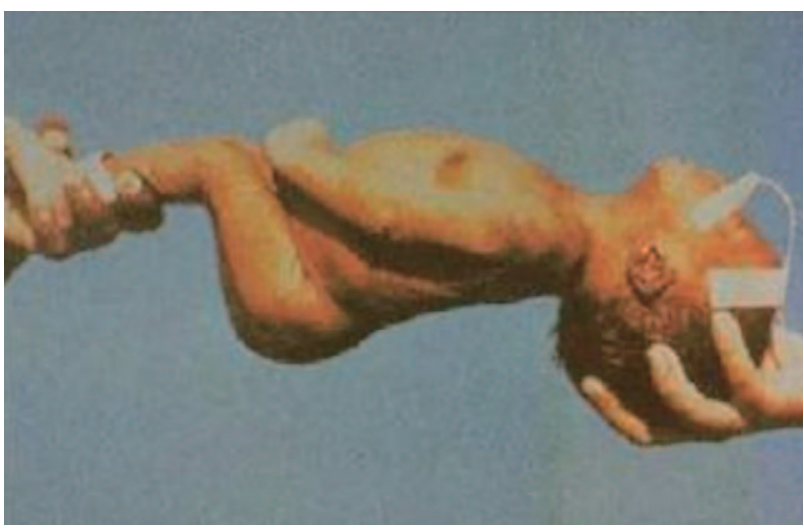

Fig. 1. An infant with neonatal tetanus presenting with opisthotonus (provided by the Centers for Disease Control and Prevention).

weight are associated with death ${ }^{10}$. Earlier onset, leukocytosis, and longer time between first symptom and admission are also indicators of mortality and longer hospital stay ${ }^{10)}$.

Improvement is heralded by defervescence (usually within 3-7 days), reduction in spasm episodes, and improvement of muscular rigidity. Resolution may take up to 45 days. Survivors often exhibit developmental disabilities. Newborns with severe umbilical infection are prone to bacteremia due to Enterobacteriaceae, gram-negative anaerobic bacilli (e.g., Bacteroides fragilis group), and Staphylococcus aureus $s^{11}$.

\section{Diagnosis}

The diagnosis is made on clinical grounds in the settings of increased risk, and by ruling out other potential reasons for tetanic spasm in newborns. The isolation of $C$. tetani from the stump may not be related to production of tetanospasmin. NT can be suspected once the aforementioned initial manifestations emerge. Laboratory tests are only helpful in excluding other causes. Thus, management of NT cannot be delayed pending the laboratory findings $s^{6}$.

The differential diagnosis includes pseudo-tetanus, birth injury, rabies, hypocalcemic tetany, seizure, meningitis, encephalitis, dystonic reactions to antipsychotics or other central dopamine antagonists, and strychnine poisoning ${ }^{12,13}$.
Neonatal tetany differs from NT. Newborns with tetany are well between convulsive episodes. Carpopedal spasm and laryngospasm appear in tetany, but trismus is rare. The diagnosis is established by confirming hypocalcemia ${ }^{11,14)}$.

The rigidity of newborns due to birth injury usually exhibits signs of brain injury before the initial signs of tetanus emerge. Extraocular palsies generally exist, abdominal rigidity is lacking, and response to stimulation is suppressed ${ }^{15}$.

\section{Management and outcome}

The managing goals are to neutralize its toxin, eradicate C. tetani, care for wound, and offer supportive care, such as mechanical ventilation, parenteral nutrition, sedation, neuromuscular blockade, and management of autonomic dysfunction ${ }^{16}$. Most data on this topic are based on observation or studies in adults. Survival rests on the various measures for supportive care with emphasis on intubation, administration of neuromuscular blocking agents, and providing assisted ventilation ${ }^{17,18}$. It is difficult but necessary to administer forceful, but calculated, and supportive care that eliminates any stimulus. Affected infants to an adequate setting should be transferred early in the course of illness.

\section{1) Neutralization of tetanospasmin}

The newborn should receive human tetanus immunoglobulin (TIG) without delay ${ }^{11,18)}$. TIG should be given as a single intramuscular (IM) dose of 500 $\mathrm{U}$ to bind the circulating toxin. However, the exact dose has not been determined, and total doses as high as 3,000-6,000 U are also recommended. Part of the dose can be infiltrated around the identified wound. If TIG is unavailable, equine tetanus antitoxin can be administered. When this antitoxin is given, immediate and delayed reactions to the antitoxin may take place. Although intravenous (IV) immunoglobulin offers passive immunization, there is insufficient familiarity with its dose and efficacy. Since tetanus itself does not confer an antibody response, those who underwent NT should be immu- 
nized with the series of diphtheria and tetanus toxoids and acellular pertussis vaccine (DTaP), following complete recovery from the active illness ${ }^{11,18}$.

Intrathecal administration of TIG or tetanus antitoxin enables higher concentration of TIG or antitoxin within the nervous system than IM administration. Despite the conflicting evidence on superiority of intrathecal over IM administration, a meta-analysis using 12 clinical trials involving 942 patients suggested that intrathecal administration is more beneficial than the latter ${ }^{19}$. A randomized controlled trial shows a reduced mortality in neonates who received intrathecal lyophilized human immunoglobulin while also receiving IM tetanus $\operatorname{antitoxin}^{20)}$.

\section{2) Eradication of $C$. tetani}

C. tetani is susceptible to several antimicrobials: penicillins, cephalosporins, metronidazole, macrolides, tetracyclines, and imipenem ${ }^{21-23}$. It is recommended that specific antimicrobial therapy should be given with one of these modalities: per os or IV metronidazole ( $<7$ days of age, $15 \mathrm{mg} / \mathrm{kg} /$ day in divided doses; $>7$ days, $30 \mathrm{mg} / \mathrm{kg} /$ day in divided doses, for 10-14 days); or IV penicillin G (100,000 U/kg/day administered at 6-hour intervals, for 10-14 days).

\section{3) Wound care}

In the presence of an umbilical stump infection, it may be necessary to obtain the adequate antimicrobial coverage against polymicrobial aerobic-anaerobic pathogens ${ }^{11}$. Topical application of antimicrobials or disinfectants to the umbilical cord can serve as an effective preventive measure ${ }^{16)}$. It is important to clean the wound by removing dirt, foreign object, and the dead tissue.

\section{4) Sedation and neuromuscular blockade}

Clinical experience has demonstrated that mortality rate was lowest in those treated with combined therapy of diazepam, phenobarbital sodium, and/or chlorpromazine ${ }^{211}$. Omphalectomy has also been used to eliminate the toxin production ${ }^{211}$.

Sedation and muscle relaxation in mild cases are achievable with diazepam. An initial dose of 0.1-0.2 $\mathrm{mg} / \mathrm{kg}$ IV is given to release an acute spasm, followed by a continuous IV infusion of $15-40 \mathrm{mg} / \mathrm{kg} /$ day, titrated to control the spasm. After 5-7 days, it can be decreased by $5-10 \mathrm{mg} /$ day and given orally or nasogastric ${ }^{111}$.

Concomitant phenobarbital is given with a loading dose of $20 \mathrm{mg} / \mathrm{kg}$ and maintenance dose of 5 $\mathrm{mg} / \mathrm{kg} /$ day to reach a serum phenobarbital concentration of 30-50 mg/dL. Substantial apnea occurs in about $10 \%$ of treated patients and respiratory support should be given immediately. Assisted ventilation is vital at higher doses. Other benzodiazepines, such as lorazepam and midazolam, are also acceptable. Further sedation with phenothiazines may be needed. If spasm cannot be suppressed, therapeutic paralysis is required ${ }^{10)}$.

Curariform agents, such as vecuronium, can induce neuromuscular blockade. Since these agents are often administered for extended period of time, the doses should be reduced slowly to prevent withdrawal symptoms ${ }^{10)}$.

\section{5) Management of autonomic dysfunction}

Decreasing production of catecholamines can reduce the autonomic dysfunction. Labetalol (0.25$1.0 \mathrm{mg} /$ minute) that possesses both $\alpha-$ and $\beta-$ blockade can be given. Providing only $\beta$-blockade (e.g., propranolol) is not advised because it may lead to sudden death ${ }^{18)}$. Morphine sulfate (0.5-1.0 $\mathrm{mg} / \mathrm{kg} /$ hour, continuous IV infusion) is frequently used to sedate and control the autonomic dysfunction by diminishing cardiac and vascular sympathetic tone. This drug adjusts cardiac instability without compromising ${ }^{24)}$. Only magnesium sulfate has been evaluated in a randomized clinical trial of severe tetanus ${ }^{25}$, and in several series for managing spasm including $\mathrm{NT}^{26-29)}$. Thus, magnesium sulfate is given as a first-line agent in the management of NT. It relaxes the vascular smooth muscles and decreases catecholamine release from the adrenal medulla ${ }^{30}$ and the adrenergic nerve endings ${ }^{31}$. Other medications to control the autonomic dysfunction are atropine, clonidine, and 
epidural bupivacaine $e^{32,33)}$.

6) Other measures for supportive care

Nutritional support is important, and should be provided early to satisfy the neonates' high caloric and protein demands ${ }^{34)}$. Enteral feeding is rarely utilized. Instead, a percutaneous endoscopic gastrostomy tube is frequently used in decreasing gastroesophageal reflux than a nasogastric tube. Central venous hyperalimentation may also be used. Heparins or other anticoagulants are given to prevent thromboembolism. Flotation bed or frequent position changes can prevent skin breakdown and peroneal nerve palsies $^{26,27)}$.

\section{7) Outcome}

Many survivors from NT experience developmental handicaps. Only a few studies evaluated the longterm effects of this entity. Furthermore, actual rates of sequelae are likely to be greater. A Kenyan study shows that $20 \%-40 \%$ of survivors sustained permanent brain damage, manifested as microcephaly, and neurological, developmental, and behavioral difficulties $^{35)}$. A Nigerian case series shows cerebral palsy, cognitive-developmental delay, and deafness in $20 \%$ of survivors ${ }^{36)}$. These complications might have been caused by the hypoxia and hypoglycemia that are frequent throughout the illness.

\section{Prevention}

The World Health Organization recommends the administration of 6 doses (3 primary plus 3 booster ones) of tetanus toxoid-containing vaccines to each child. The 3 -dose primary series should start at the age of 6 weeks, followed by 3 boosters given 4 weeks apart ${ }^{37}$. It is recommended that the 3 boosters are given in the second year of life, and additional single booster doses at 4-7 years and at 9-15 years. Ideally, there should be at least 4 years between booster doses.

To prevent the occurrence of NT, pregnant women should receive 1 dose of reduced diphtheria and pertussis toxoids (Tdap) during each pregnancy, preferably during 27-36 weeks of gestation ${ }^{37,38)}$. Previously unvaccinated pregnant women should receive 2 doses of tetanus toxoid (at least 1 dose of Tdap) given 1 month apart, with the first dose as early as possible in pregnancy ${ }^{2,37)}$. Further doses should be given in subsequent pregnancies or at intervals of at least 1 year, up to a total of 5 doses that is considered sufficient for the lifelong protection ${ }^{2)}$.

\section{Conclusion}

NT is one of the most common life-threatening consequences of unhygienic deliveries and umbilical cord management. This entity is an indicator of inadequate availability of immunization and other maternal and neonatal care. NT-related mortality rates are high mainly when inadequate health care is provided as often occurs in developing countries. The managing goals are neutralization of toxin, eradication of $C$. tetani, wound care, and specific supportive care. Mortality can be averted easily by practicing sanitary delivery and adequate cord care or by vaccinating children and women with tetanus toxoid-containing vaccines.

\section{ORCID}

Itzhak Brook (https://orcid.org/0000-0001-6068-1475)

\section{Conflicts of interest}

No potential conflicts of interest relevant to this article were reported.

\section{Acknowledgements}

No funding source relevant to this article was reported. 


\section{References}

1. Centers for Disease Control and Prevention (CDC). Summary of notifiable disease-United States, 2010. MMWR Morb Mortal Wkly Rep 2012;59:1-111.

2. Thwaites CL, Beeching NJ, Newton CR. Maternal and neonatal tetanus. Lancet 2015;385:362-70.

3. World Health Organization (WHO). Maternal and neonatal tetanus elimination (MNTE) [Internet]. Geneva: WHO; c2021 [cited 2021 Jan 29]. Available from: https://www.who.int/immunization/diseases/MNTE_initiative/en/.

4. Jorgensen JH, Pfaller MA, Carroll KC; American Society for Microbiology, editors. Manual of clinical microbiology. 11th ed. Washington, DC: ASM Press; 2015. p. 940-66.

5. Dong M, Masuyer G, Stenmark P. Botulinum and tetanus neurotoxins. Annu Rev Biochem 2019;88:811-37.

6. Yen LM, Thwaites CL. Tetanus. Lancet 2019;393:1657-68.

7. Chen S. Clostridial neurotoxins: mode of substrate recognition and novel therapy development. Curr Protein Pept Sci 2014;15:490-503.

8. Hubbard K, Beske P, Lyman M, McNutt P. Functional evaluation of biological neurotoxins in networked cultures of stem cell-derived central nervous system neurons. J Vis Exp 2015;96:52361.

9. Vannini E, Caleo M, Chillemi S, Di Garbo A. Dynamical properties of LFPs from mice with unilateral injection of TeNT. Biosystems 2017;161:57-66.

10. Lam PK, Trieu HT, Lubis IN, Loan HT, Thuy TT, Wills B, et al. Prognosis of neonatal tetanus in the modern management era: an observational study in 107 Vietnamese infants. Int J Infect Dis 2015;33:7-11.

11. Brook I. Anaerobic bacteria in omphalitis. Pediatr Infect Dis 1985;4:704.

12. Pileggi DJ, Cook AM. Neuroleptic malignant syndrome. Ann Pharmacother 2016;50:973-81.

13. Hur MH, Havalad V, Clardy C. Strychnine: old remedy, silent killer. Pediatr Ann 2019;48:e205-07.

14. Vuralli D. Clinical approach to hypocalcemia in newborn period and infancy: who should be treated? Int J Pediatr 2019;2019:4318075.

15. Mine J, Taketani T, Yoshida K, Yokochi F, Kobayashi J, Maruyama K, et al. Clinical and genetic investigation of 17 Japanese patients with hyperekplexia. Dev Med Child Neurol 2015;57:372-7.

16. Amare Y. Umbilical cord care in Ethiopia and implications for behavioral change: a qualitative study. BMC Int Health Hum Rights 2014;14:12.

17. Rodrigo C, Fernando D, Rajapakse S. Pharmacological management of tetanus: an evidence-based review. Crit Care 2014; 18:217.

18. American Academy of Pediatrics. Tetanus. In: Committee on Infectious Diseases; American Academy of Pediatrics;
Kimberlin DW, Brady MT, Jackson MA, Long SS, editors. Red Book. 31st ed. Itasca (IL): American Academy of Pediatrics; 2018. p. 793-8.

19. Kabura L, Ilibagiza D, Menten J, Van den Ende J. Intrathecal vs. intramuscular administration of human antitetanus immunoglobulin or equine tetanus antitoxin in the treatment of tetanus: a meta-analysis. Trop Med Int Health 2006;11: 1075-81.

20. Ahmad A, Qaisar I, Naeem M, Mazhar AU, Ashfaq M. Intrathecal anti-tetanus human immunoglobulin in the treatment of neonatal tetanus. J Coll Physicians Surg Pak 2011;21:539-41.

21. Wang X, Yu R, Shang X, Li J, Gu L, Rao R, et al. Multicenter study of tetanus patients in Fujian Province of China: a retrospective review of 95 cases. Biomed Res Int 2020;2020: 8508547.

22. Hanif H, Anjum A, Ali N, Jamal A, Imran M, Ahmad B, et al. Isolation and antibiogram of Clostridium tetani from clinically diagnosed tetanus patients. Am J Trop Med Hyg 2015;93:752-6.

23. Onuki T, Nihonyanagi S, Nakamura M, Ide T, Hattori J, Kanoh $\mathrm{Y}$, et al. Clostridium tetani isolated from patients with systemic tetanus. Kansenshogaku Zasshi 2013;87:33-8.

24. Tane N, Okuda N, Imanaka H, Nishimura M. Neurally adjusted ventilatory assist improves patient-ventilator synchrony in a patient with tetanus and unstable diaphragmatic electrical activity. Respir Care 2015;60:e76-9.

25. Thwaites CL, Yen LM, Loan HT, Thuy TT, Thwaites GE, Stepniewska K. et al. Magnesium sulphate for treatment of severe tetanus: a randomised controlled trial. Lancet 2006; 368:1436-43.

26. Trieu HT, Lubis IN, Qui PT, Yen LM, Wills B, Thwaites CL, et al. Neonatal tetanus in Vietnam: comprehensive intensive care support improves mortality. J Pediatric Infect Dis Soc 2016;5:227-30.

27. Wen SC, Webb C, Miles F, Wilson E. Tetanus in New Zealand children: intensive care management of a vaccine preventable disease. J Paediatr Child Health 2016;52:1070-4.

28. Shanbag P, Mauskar A, Masavkar S. Intravenous magnesium sulphate infusion as first-line therapy in the control of spasm and muscular rigidity in childhood tetanus. Paediatr Int Child Health 2019;39:201-7.

29. Puliyel MM, Pillai R, Korula S. Intravenous magnesium sulphate infusion in the management of very severe tetanus in a child: a descriptive case report. J Trop Pediatr 2009;55: 58-9.

30. Lishajko F. Releasing effect of calcium and phosphate on catecholamines, ATP, and protein from chromaffin cell granules. Acta Physiol Scand 1970;79:575-84.

31. von Euler US, Lishajko F. Effects of $\mathrm{Mg}^{2+}$ and $\mathrm{Ca}^{2+}$ on 
noradrenaline release and uptake in adrenergic nerve granules in differential media. Acta Physiol Scand 1973;89:41522.

32. Brook I. Current concepts in the management of Clostridium tetani infection. Expert Rev Anti Infect Ther 2008;6:327-36.

33. Rhinesmith E, Fu L. Tetanus disease, treatment, management. Pediatr Rev 2018;39:430-2.

34. Sun C, Zhao H, Lu Y, Wang Z, Xue W, Lu S. et al. Prognostic factors for generalized tetanus in adults: a retrospective study in a Chinese hospital. Am J Emerg Med 2019;37:254-9.

35. Barlow JL, Mung'Ala-Odera V, Gona J, Newton CR. Brain damage after neonatal tetanus in a rural Kenyan hospital. Trop Med Int Health 2001;6:305-8.
36. Mchil Ugwu GI, Okolugbo NE. Neonatal tetanus in Warri Niger Delta: a ten year retrospective study. Cont J Med Res 2010;4:3-7.

37. Havers FP, Moro PL, Hunter P, Hariri S, Bernstein H. Use of tetanus toxoid, reduced diphtheria toxoid, and acellular pertussis vaccines: updated recommendations of the Advisory Committee on Immunization Practices - United States, 2019. MMWR Morb Mortal Wkly Rep 2020;69:77-83.

38. Schleiss MR. Tetanus (Clostridium tetani). In: Kliegman RM, St Geme JW 3rd, Blum NJ, Shah SS, Tasker RC, Wilson KM, editors. Nelson textbook of pediatrics. 21th ed. Philadelphia (PA): Elsevier: 2015. p. 1549-51. 